\title{
Cardiovascular medicine in primary healthcare in sub-Saharan Africa: Minimum standards for practice (part 3)
}

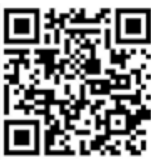

Cardiovascular disease (CVD) is the leading cause of death worldwide. Approximately $80 \%$ of all cardiovascular-related deaths occur in low- to middleincome countries and at a younger age compared with high-income countries. ${ }^{[1]}$ The economic burden imposed by CVD on developing countries in terms of loss of productive years of life and amount of fiscal resources spent on secondary and tertiary care is considerably high.

A sizeable proportion of the population-attributable risk for myocardial infarction is accounted for by nine modifiable risk factors, regardless of the geographical region. ${ }^{[2]}$ Heart failure is an important cause of morbidity and mortality in sub-Saharan Africa (SSA) and the spectrum of aetiology in this region is different from that in many high-income countries. ${ }^{[3,4]}$

In Africa, there are major concerns with regard to the success of strategies for primary and secondary prevention of CVD ${ }^{[1]}$ Challenges include lack of epidemiological and outcome data, limited national resources, poor political will and motivation, suboptimal healthcare infrastructure, low numbers of appropriately skilled healthcare personnel and lack of prediction models in many populations. Sadly, available data suggest that CVD is poorly managed in SSA. ${ }^{[5,6]}$

This issue of CME focuses on the clinical approaches to common cardiovascular challenges. It forms the third part of a series of articles jointly produced by South African (SA) cardiologists and family physicians with the dual objectives of empowering doctors who manage these conditions in primary care settings in SA and improving the care of CVD patients in such settings and emergency departments. In the first issue, heart failure, ${ }^{[7]}$ dyspnoea, ${ }^{[8]}$ hypertension in the young ${ }^{[9]}$ and valvular heart disease ${ }^{[10]}$ were reviewed. In the second issue, the important clinical problems of infective endocarditis ${ }^{[11]}$ and pericardial disease ${ }^{[12]}$ were discussed. The current edition provides an evidence-based and pragmatic approach to acute coronary syndromes and chest pain, ${ }^{[13]}$ and suspected tachyarrhythmias in the emergency room. ${ }^{[14]}$

Pandie et al. ${ }^{[13]}$ discuss the approach to chest pain and acute myocardial infarction. The history and physical examination are the mainstay of clinical assessment, and are complemented by a 12-lead electrocardiogram (ECG) and cardiac biomarkers for correct diagnosis. Chest pain is a common presentation at emergency rooms. The first priority should always be to ensure rapid and accurate diagnosis of serious acute chest pain syndromes, including acute coronary syndromes (ACSs), aortic dissection, pulmonary embolism, cardiac tamponade, tension pneumothorax, and acute abdominal syndromes.

Elevated serum cardiac biomarkers provide evidence of myocardial cell injury. While the ECG is a crucial investigative tool, unfortunately many primary and secondary hospitals in SA and throughout SSA lack this equipment (or, if present, have no ECG strips, and the machines are not calibrated regularly). Despite these shortcomings, the authors present what should be the standard approach to chest pain and acute myocardial infarction. For example, the Marburg Heart Score, which has an excellent negative predictive value, can be used at a primary care level in the absence of a functional ECG machine.

A systematic approach to the evidence-based management of ACSs is discussed. The management of ST elevation myocardial infarction (STEMI) patients includes providing the fastest and safest method of reperfusion therapy available - primary percutaneous coronary intervention or fibrinolysis, while initiating essential adjunctive therapies (antiplatelet therapy - aspirin with $\mathrm{P}_{2} \mathrm{Y}_{12}$ inhibitors, anticoagulation heparin or low-molecular-weight heparin), and cardiac monitoring.

In the emergency or primary healthcare setting, patients often present with tachycardia or a history of palpitations, which may lead the doctor to suspect an underlying tachycardia. Chin et al. ${ }^{[14]}$ review the mechanisms, diagnostic evaluation and management of tachycardia.

A narrow complex tachycardia or supraventricular tachycardia usually has a QRS duration of $<120 \mathrm{~ms}$, unless there is bundle branch block or an intraventricular conduction abnormality. Supraventricular tachycardia comprises a wide range of arrhythmias that have their origin above the bifurcation of the bundle of His, encompassing sinus tachycardia, atrial flutter, atrial fibrillation, atrial tachycardia, atrioventricular junctional re-entrant tachycardia, including atrioventricular nodal re-entrant tachycardia, atrioventricular re-entrant tachycardia and junctional ectopic tachycardia.

A wide complex tachycardia has a QRS duration $\geq 120 \mathrm{~ms}$ and may be caused by one of the following mechanisms: (i) ventricular tachycardia, which must be the default diagnosis in any patient with a wide complex tachycardia; (ii) supraventricular tachycardia with a right or left bundle branch block or an intraventricular conduction abnormality; (iii) pre-excited tachycardia (Wolff-Parkinson-White syndrome) over an accessory pathway; and (iv) pacemaker tachycardia.

A complete history should cover the heart rate and regularity, mode of onset and termination, precipitating factors, associated symptoms, and any associated heart disease. The ECG is the hallmark of diagnosis. One may classify tachycardia into narrow (supraventricular) tachycardia and wide complex tachycardia, which may be regular or irregular, and the differential diagnosis of each of these categories should be considered.

It is our sincere hope that this series of articles on common cardiovascular conditions often encountered in primary care settings in SA and SSA will improve the care of patients with CVD. Furthermore, it is our wish that the articles clearly emphasise the minimum standards for management of these common cardiovascular disorders.

\section{Gboyega Ogunbanjo}

Guest editor

Department of Family Medicine and

Primary Health Care, Sefako Makgatho Health

Sciences University, Pretoria, South Africa

profbanjo@gmail.com

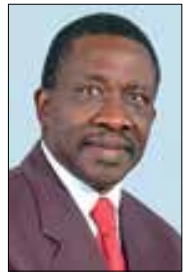

\section{Ntobeko A B Ntusi}

Guest editor

Division of Cardiology, Department of Medicine, Faculty of Health Sciences, University of

Cape Town and Groote Schuur Hospital,

Cape Town, South Africa

ntobeko.ntusi@gmail.com

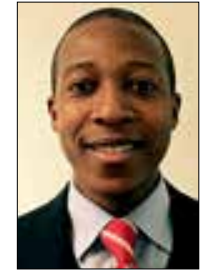


1. Gersh BJ, Sliwa K, Mayosi BM, Yusuf S. The epidemic of cardiovascular disease in the developing world: Global implications. Eur Heart J 2010;31:642-648. [http://dx.doi.org/10.1093/eurheartjehq030]

2. Yusuf $S$, Hawken S, Ounpuu S, et al. Effect of potentially modifiable risk factors associated with

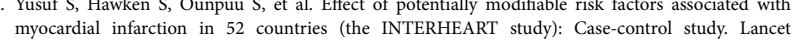
2004;364(9438):937-952

3. Ntusi NAB, Mayosi BM. Epidemiology of heart failure in sub-Saharan Africa. Expert Rev Cardiovasc Ther 2009;7:169-180. [http://dx.doi.org/10.1586/14779072.7.2.169]

4. Damasceno A, Mayosi BM, Sani M, et al. The causes, treatment, and outcome of acute heart failure in 1006 Africans from 9 countries. Arch Intern Med 2012;172(18):1386-1394.

5. Steyn K. Heart Disease in South Africa. Cape Town: Medical Research Council: The Heart and Stroke Foundation of South Africa, 2007. http://www.mrc.ac.za/chronic/heartandstroke.pdf (accessed 6 December 2015)

6. Ntusi NAB. Dismal management of hypertension at primary level: Does it reflect a failure of patients, a failure of the system or a failure of doctors? Cardiovasc J Afr 2011;22(4):172-174.

7. Kraus S, Ogunbanjo G, Sliwa K, Ntusi NAB. Heart failure in sub-Saharan Africa: A clinical approach. S Afr Med J 2016;106(1):23-31. [http://dx.doi.org/10.7196/SAMJ.2016.v106i1.10325]

8. Coccia CBI, Palkowski GH, Schweitzer B, Motsohi T, Ntusi NAB. Dyspnoea: Pathophysiology and a

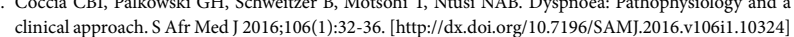

9. Mangena P, Saban S, Hlabyago KE, Rayner B. An approach to the young hypertensive patient. S Afr Med J 2016;106(1):36-38. [http://dx.doi.org/10.7196/SAMJ.2016.v106i1.10329]

10. Cupido B, Peters F N Nusi NAB. An approach to the diagnosis and management of valvular heart disease. S Afr Med J 2016;106(1):39-42. [http://dx.doi.org/10.7196/SAMJ.2016.v106i1.10326]

11. Hitzeroth J, Beckett N, Ntuli P. An approach to the patient with infective endocarditis. S Afr Med J 2016;106(2):145-150. [http://dx.doi.org/10.7196/SAMJ.2016.v106i2.10327]

12. Kyriakakis CG, Mayosi BM, de Vries E, Isaacs A, Doubell AF. An approach to the patient with suspected pericardial disease. S Afr Med J 2016;106(2):151-155. [http://dx.doi.org/10.7196/SAMJ.2016. v106i2.10328]

13. Pandie S, Hellenberg D, Hellig F, Ntsekhe M. An approach to chest pain and acute myocardi infarction. S Afr Med J 2016;106(3):239-245. [http://dx.doi.org/10.7196/SAMJ.2016.v106i3.10323]

14. Chin A, Vezi B, Namane M, Weich H, Scott-Millar R. An approach to the patient with suspected tachycardia in the emergency department. S Afr Med J 2016;106(3):246-250. [http://dx.doi. org/10.7196/SAMJ.2016.v106i3.10322

S Afr Med J 2016;106(3):237-238. DOI:10.7196/SAMJ.2016.v106i3.10593 